\title{
Un nuevo reto para
}

la Administración: el

reconocimiento de la

selva del Amazonas

como sujeto de

protección por el juez de

tutela

Nicolás CABezas ${ }^{1}$

\section{RESUMEN}

El creciente deterioro ambiental de la selva del Amazonas constituye una violación directa al derecho al ambiente sano de generaciones actuales y futuras. Pese a una copiosa normatividad a favor de la protección del medio ambiente, las cifras de deforestación muestran un panorama desalentador. Mediante acción de tutela se buscó obligar a varios entes territoriales y organismos del orden nacional a cumplir con sus obligaciones de rango internacional, constitucional y legal en materia medioambiental. Este escrito pretende ubicar la argumentación dada por el juez de tutela dentro de diferentes teorías del derecho, con el fin de exponer soluciones alternativas. Se intenta poner en

1 Estudiante y monitor del Departamento de Derecho Administrativo, Universidad Externado de Colombia, Bogotá, Colombia. Correo-e: nicolas.cabezas@est.uexternado. edu.co. Fecha de recepción: 30 de abril de 2018. Fecha de modificación: 15 de mayo de 2018. Fecha de aceptación: 20 de mayo de 2018. Para citar el artículo: Cabezas ManOSALVA, NiCOLÁs, "Un nuevo reto para la Administración: el reconocimiento de la selva del Amazonas como sujeto de protección por el juez de tutela", Revista digital de Derecho Administrativo, Universidad Externado de Colombia, n. ${ }^{\circ} 20$, 2018, pp. 465-483. DOI: https://doi. org/10.18601/21452946.n20.17. 
evidencia posibles contradicciones y puntos de convergencia en la solución de este "caso difícil", que llevó al reconocimiento de un nuevo sujeto de derecho.

Palabras clave: Administración territorial y nacional, Selva del Amazonas, Nuevo sujeto de derecho, Protección del medio ambiente, Positivismo jurídico, Realismo jurídico.

\section{A New Challenge for the Administration: The Recognition of the Amazon Jungle as Subject of Legal Protection by the Colombian Jurisprudence}

\section{ABSTRACT}

The increasing environmental devastation of the Amazon jungle constitutes a direct violation of the right to a healthy environment of current and future generations. Despite a significant environmental regulation, the figures of deforestation show a discouraging panorama. Through a legal action aimed at protecting fundamental rights (tutela), the plaintiffs sought to compel national, departmental and local authorities to fulfil their legal duties with regards to the natural environment. This paper intends to place the reasoning behind the decision of this case, which recognize the Amazon jungle as a legal entity subject of rights, among different legal theories. It attempts to present alternative solutions and to expose possible contradictions and points of convergence in the decision of a difficult case.

Keywords: National and Territorial Administration, Amazon Jungle, New Subject of Rights, Environmental Protection, Legal Positivism, Legal Realism.

\section{LA DEFORESTACIÓN EN EL AMAZONAS COMO VIOLACIÓN PRESENTE Y FUTURA DE DERECHOS CONSTITUCIONALES}

El pasado 5 de abril de $2018^{[2]}$, la Corte Suprema de Justicia decidió en segunda instancia una tutela en contra de 27 entidades del nivel nacional y territorial $^{3}$ por la violación de los derechos al ambiente sano, a la vida y la salud. Los

2 Corte Suprema de Justicia, sentencia de 5 de abril de 2018, expediente 11001-22-03-0002018-00319-01.

3 Entre otros, el presidente de la República, el Ministerio de Medio Ambiente y Desarrollo Sostenible, el Ministerio de Agricultura y Desarrollo Rural, la Fiscalía General de la Nación, 
accionantes consideraban que la afectación a los derechos fundamentales era el resultado de la creciente deforestación en la selva de la Amazonía. De esta manera, su petición iba encaminada a obtener protección frente al aumento proyectado para el año 2070 de entre 1,6 y 2,14 grados centígrados en la temperatura del planeta, aumento que, de acuerdo con la proyección de vida, sería sufrido por los accionantes durante su vida adulta, sumado a las afectaciones que esto tendría sobre las reservas de recursos hídricos.

El argumento de los accionantes gira fundamentalmente alrededor de los siguientes hechos:

- De acuerdo con el Boletín de Alertas Tempranas de Deforestación (AT-D) del primer semestre de 2017 del Ministerio de Medio Ambiente y el IDEAM, "la Amazonía es la región con mayor AT-D del país, con un 66,2\% del total".

- Las alarmantes cifras de deforestación de la selva de la Amazonía ${ }^{4}$, cuya causa es atribuida al "acaparamiento de tierras (60-65\%), los cultivos de uso ilícito (20-22\%), la extracción ilícita de yacimientos minerales (7-8\%), la infraestructura, los cultivos agroindustriales y la extracción ilegal de madera".

- La afectación al ciclo del agua, la capacidad del suelo para absorber líquidos, el suministro de agua a los páramos y el cambio climático resultado de los puntos anteriores.

Partiendo de estos hechos, se considera que es la omisión y falta de aplicación de las normas existentes ${ }^{5}$ por las autoridades accionadas las que han permitido el deterioro de este ecosistema y, de no tener amparo, las que permitirán que las

la Unidad Administrativa Especial de Parques Nacionales Naturales y las gobernaciones de Amazonas, Caquetá, Guainía, Guaviare, Putumayo y Vaupés.

4 De esta manera, en la "Estrategia Integral de Control a la Deforestación y Gestión de los Bosques en Colombia", la mencionada cartera informó que "el país perdió 178.597 hectáreas en el año 2016, es decir, la deforestación aumentó en $44 \%$ respecto a la cifra reportada para 2015", y, de ese número, "70.074 hectáreas corresponden a la Amazonía".

5 Se debe partir desde la constitución que en varios artículos consagra la obligación del Estado de proteger los recursos naturales (art. 8), el derecho al saneamiento ambiental (art. 49), la función ecológica de la propiedad privada (art. 58), el derecho a un ambiente sano (art. 79), el deber del estado de garantizar un desarrollo sostenible (art. 80), la obligación de explotación racional y sostenible de los recursos naturales y protección del medio ambiente (art. 334), el deber ciudadano de proteger los recursos naturales y velar por la protección del ambiente (art. 95.8). Esto sumado a diferentes leyes como el Decreto 2811 de 1975 (Código Nacional de Recursos Naturales Renovables y de Protección al Medio Ambiente), la Ley 99 de 1993 (por la cual se crea un ministerio encargado de la protección del medio ambiente), la Ley 9 de 1989 (reformada por la 3881997 y que contiene obligaciones de preservación medio ambiental a cargo de las entidades territoriales); también convenios internacionales como Protocolo de Montreal relativo a las sustancias agotadoras de la capa de ozono (ratificado por la Ley 29 de 1992), el Convenio de Estocolmo sobre Contaminantes Orgánicos Persistentes (ratificado por la Ley 1196 de 2008), el Tratado de Cooperación Amazónica (ratificado por la Ley 74 de 1979), el reciente acuerdo de París sobre el cambio climático de 2015 (ratificado por la Ley 1844 de 2017), entre otras normas. 
proyecciones se materialicen a futuro. De este modo, los accionantes justifican la procedencia de la acción en la medida de que no solo han sido vulnerados derechos colectivos, sino también derechos fundamentales individuales. En su defecto, piden que proceda la tutela como mecanismo transitorio para evitar un perjuicio irremediable.

La primera instancia, decidida por la Sala Civil Especializada en Restitución de Tierras del Tribunal Superior del Distrito Judicial de Bogotá, optó por desestimar las pretensiones considerando que la tutela no resultaba un medio idóneo para la protección de este tipo de derechos.

Como se desprende de lo anterior, los problemas jurídicos presentados ante la Corte fueron saber si se cumple con los requisitos de procedencia de la acción de tutela como mecanismo de protección indirecta de derechos colectivos y, en un juicio de imputación, si resulta atribuible a las autoridades accionadas el daño consistente en la deforestación de la Amazonía y su constante crecimiento. Debe ponerse de presente que, aunque no fue objeto directo del litigio, también se respondió a la siguiente pregunta: ¿se debe reconocer al conjunto de seres vivos de la selva de la Amazonía como un sujeto de derechos para asegurar su protección constitucional?

Se examinan en el presente escrito los argumentos dados por el juez de tutela, en desarrollo de los problemas jurídicos aquí planteados, con el fin de identificar a qué teoría del derecho corresponde el razonamiento detrás del fallo objeto del presente escrito. Esto permitirá determinar si hay soluciones alternativas, desde otras perspectivas filosóficas del derecho. Lo anterior no significa que los resultados serán necesariamente contrapuestos, se mostrarán, por tanto, ciertos puntos de convergencia y, a su vez, puntos irreconciliables entre las diferentes posturas.

\section{DE LA PROCEDENCIA DE LA ACCIÓN DE TUTELA}

Para la jurisprudencia constitucional no resulta extraña la utilización de la tutela para la protección indirecta de derechos colectivos. En efecto, se ha considerado que en caso de que exista conexidad directa entre la afectación de un derecho fundamental y otro de carácter colectivo, será procedente la acción de tutela si se prueba la insuficiencia de la acción popular ${ }^{6}$ y se

6 " $[\ldots]$ al momento de analizar si la acción de tutela es procedente para proteger un derecho colectivo, el juez constitucional debe recordar siempre que, en principio, existe un mecanismo destinado para ello que es la acción popular. Sin embargo, excepcionalmente ha considerado procedente la tutela cuando, además de un derecho colectivo, se afecta un derecho individual fundamental y los medios de defensa a disposición del tutelante no son idóneos -como la acción popular-o en el caso se advierte un inminente perjuicio irremediable de naturaleza iusfundamental". Corte Constitucional, sentencia T-362 de 2014. 
demuestra plenamente un daño que recaiga directamente sobre los tutelantes ${ }^{7}$. A esto se añade la condición de que el fallo no debe estar encaminado al restablecimiento del derecho colectivo, sino del derecho fundamental individual, lo cual indirectamente puede llevar a la protección del primero ${ }^{8}$.

Una vez fijados los parámetros de evaluación de nuestro sistema jurídico, se podrá ubicar la postura del juez de tutela, en principio, bajo parámetros positivistas. De esta forma, la Corte Suprema optó por reiterar los criterios fijados de acuerdo con las reglas de adjudicación ${ }^{9}$, lo cual conllevaría a la solución de un "caso fácil"10. Teóricamente encontraríamos aquí un punto de convergencia entre las posturas formalista y positivista, en la medida de que se trataría de una mera aplicación de la norma vigente cuestionando la posibilidad de un margen de discrecionalidad para el juez ${ }^{11}$. Ahora bien, el juez de tutela se alejó de esta aplicación sencilla del ordenamiento en este fallo.

Al momento de realizar un examen de los criterios de procedencia de la tutela, se argumentó la conexidad entre los derechos de a la vida, salud, libertad, dignidad humana y la protección de un medio ambiente sano. La Corte Suprema consideró que el ambiente sano es punto de partida para la realización de los derechos mencionados, e incluso lo posicionó como un requisito para la existencia de los seres sintientes y, por tanto, también de la familia, el Estado y la sociedad misma. De acuerdo con este planteamiento, una afectación al ecosistema tiene conexión directa con la calidad del aire, con las reservas los recursos hídricos y, en general, con las condiciones dignas de existencia. A partir de esto se justifica una real afectación a los derechos de los tutelantes y su núcleo familiar, ante un daño que se entiende desde ya como cierto.

7 En la sentencia SU-1116 de 2001 fueron recopilados estos criterios, los cuales han sido constantemente reiterados en la jurisprudencia constitucional en sentencias como T-299 de 2008, T-734 de 2009, T-312 de 2012, T-429 de 2013, T-362 de 2014, T-341 de 2016, T-061 de 2017, entre otras.

8 Reiterado en la T-197 de 2014.

9 CéSAR Rodríguez, La decisión judicial. El debate Hart-Dworkin, Bogotá: Siglo del Hombre Universidad de los Andes, 1997, p. 26.

10 Resulta fundamental para efectos del presente trabajo acudir al concepto de caso difícil en contraposición al de caso fácil. Se entenderá como caso difícil aquella situación relevante para el derecho que no encuentra una regulación expresa en el ordenamiento jurídico o, que de tenerla, resulta en una decisión contraria al concepto abstracto de justicia (materializado en los principios del sistema jurídico o, dependiendo de la teoría del derecho adoptada, en los criterios del juez). Se trata, por tanto, de la consecuencia de la imposibilidad del derecho de regular todas las conductas que planteaba Hart, es decir, la "zona de penumbra" en la aplicación de los principios según Dworkin, la cual, sin embargo, raras veces es aceptada por los operadores judiciales en la medida de que, sin reconocerla expresamente, la solucionan argumentando con seguridad la titularidad de un derecho u otro, a pesar de las posibles inconsistencias sistemáticas en las que puedan caer, como se verá en el presente caso. Scott Shapiro, Legalidad, Madrid: Marcial Pons, 2014, p. 321.

11 Ibíd., p. 297. 
Bajo esta línea argumentativa, tendríamos un pleno cumplimiento de los requisitos de procedencia de la acción de tutela, a excepción de aquel que exige demostrar la insuficiencia de la acción popular como medio de protección ${ }^{12}$. Encontramos aquí un punto de divergencia entre las tesis mencionadas, puesto que el juez de tutela, lejos de argumentar a favor de los beneficios del mecanismo utilizado de cara a la acción popular o acerca de cómo esta última era insuficiente para asegurar una protección real de los derechos afectados, optó por señalar la urgencia de tomar medidas inmediatas ${ }^{13} \mathrm{y}$ el problema práctico de delimitar el ámbito de aplicación de las dos acciones constitucionales.

Con relación a este último argumento hay posiciones encontradas. Si bien en un principio se planteaba la prevalencia de los derechos de orden individual y el deber del juez de ordenar las medidas necesarias para su protección ${ }^{14}$, también la jurisprudencia constitucional ha optado por el carácter subsidiario de la acción de tutela, por lo cual su procedencia resulta limitada a los casos en los que no sea posible otro mecanismo de protección ${ }^{15}$. Por lo tanto, al momento de decidir sobre la procedencia de la tutela, el juez del caso consideró

12 No se ha dejado de lado el punto referente a que el fallo deberá orientarse a la reparación del derecho individual vulnerado, pues más que un criterio de procedencia responde a una regla al momento del fallo. Elemento sobre el que volveremos más adelante.

13 A pesar de las amplias facultades contenidas el artículo 25 de la Ley 472 de 1998, respecto de las medidas cautelares del proceso de acción popular. De esta manera, "el legislador definió claramente los criterios que deben tenerse en cuenta para evaluar los casos en los que procede la acción popular, dotando a este mecanismo de herramientas óptimas para lograr una pronta protección de los derechos colectivos de las personas, como por ejemplo, la facultad que el juez de conocimiento tiene para decretar medidas cautelares una vez admita la acción y la fijación de términos perentorios para la práctica de pruebas y la adopción de un fallo definitivo". Corte Constitucional, sentencia T-362 de 2014.

14 "Fundamental advertencia sobre este punto es aquella que señala de modo indubitable que este derecho constitucional (gozar de un ambiente sano) puede vincularse con la violación de otro derecho fundamental como la salud, la vida o la integridad física entre otros, para obtener, por vía de la tutela que establece el artículo 86 de la Constitución Nacional, el amparo de uno y otros derechos de origen constitucional, pues en estos casos prevalece la protección del derecho constitucional fundamental y es deber del juez remover todos los obstáculos, ofensas y amenazas que atentan contra éste. En estos casos, como se ha dicho, el Juez al analizar la situación concreta que adquiera las señaladas características de violación de un derecho constitucional fundamental deberá ordenar la tutela efectiva que se reclama". Corte Constitucional, sentencia SU-442 de 1997.

15 Así, la Corte Constitucional realizando un análisis de su jurisprudencia desde el año 2000, concluye que: "al momento de analizar si la acción de tutela es procedente para proteger un derecho colectivo, el juez constitucional debe recordar siempre que, en principio, existe un mecanismo destinado para ello que es la acción popular. Sin embargo, excepcionalmente ha considerado procedente la tutela cuando, además de un derecho colectivo, se afecta un derecho individual fundamental y los medios de defensa a disposición del tutelante no son idóneos -como la acción popular- o en el caso se advierte un inminente perjuicio irremediable de naturaleza iusfundamental". Corte Constitucional, sentencia T-362 de 2014, reiterado en sentencia T-061 de 2017. 
que independientemente de que procedan otros mecanismos (con medidas inmediatas o preventivas del daño), se estaba ante una violación de derechos fundamentales individuales "ponderación", ante la cual "deben primar los derechos fundamentales".

En anteriores oportunidades, la Sala de Casación Civil de la Corte Suprema de Justicia ha podido pronunciarse sobre la procedencia de la tutela para proteger derechos colectivos. Particularmente en sentencia de tutela del 9 de junio de $2016^{[16]}$, la Corporación decidió un caso relacionado con la afectación al medioambiente sano como resultado de un derrame de petróleo. En dicha sentencia se consideró procedente la acción de tutela por existir, al momento del examen del caso, una afectación directa y grave a los derechos fundamentales de los tutelantes, toda vez que estos no solo no habían podido acceder a suministros de agua potable, sino que además habían acreditado un historial de afectaciones a su salud por el daño ambiental producido. Asimismo, el mismo juez en sede de tutela había sido enfático al señalar que esta acción constituye un mecanismo excepcional que no puede volverse "una vía paralela ni sustitutiva de los instrumentos ordinarios o extraordinarios de defensa"17.

De esta manera, es necesario preguntarse si se estaba ante una grave afectación de derechos fundamentales individuales como en el primero de los casos que viene de ser mencionado. Con independencia de la pertinencia o necesidad de las medidas ordenadas por la Corte, se considera que no se está ante una hipótesis igual a la ocurrida en el caso fallado el 9 de junio de 2016. Esto, debido a que no se presenta una grave afectación a derechos fundamentales en el tiempo presente. De hecho, la solicitud de amparo va desde el inicio dirigida a la protección de las posibles consecuencias de no dar un buen manejo ambiental a la selva de la Amazonía. Si bien se trata de un daño progresivo que puede desencadenar en violaciones a los derechos fundamentales de los tutelantes, dicha afectación, que es sin duda meritoria de protección judicial, puede ser correctamente solucionada ante un juez mediante el ejercicio de una acción popular ${ }^{18}$.

En un primer momento, se ubicó la postura de la Corte Suprema bajo una perspectiva positivista -esperable en nuestro ordenamiento-. En este contexto,

16 Exp. 86001-22-08-000-2016-00036-01.

17 Sentencia de tutela del 25 de febrero de 2015, M.P. Luis Armando Tolosa Villabona, exp. 05000-22-13-000-2015-00001-01.

18 Argumento que se ve reforzado al analizar las órdenes del juez de tutela. Así, todas iban dirigidas a exigir la implementación de políticas públicas para la reducción de la deforestación como un "pacto intergeneracional por la vida del amazonas colombiano (PIVAC)", o la implementación de planes ambientales en los РОT, entre otras. No se encontró orden para tutelar directamente los derechos de los tutelantes, sino ordenes generales a las autoridades públicas dirigidas claramente a proteger el derecho a un ambiente sano. 
es fundamental tener en cuenta el ya mencionado ius controversum que existe en la jurisprudencia constitucional y que justifica la posibilidad de dos soluciones acordes con las prácticas constitucionales colombianas. Estas soluciones son: a) darle primacía a la protección del derecho fundamental individual, o b) hacer prevalecer el principio de subsidiaridad de la acción de tutela frente a otros mecanismos "ordinarios" previstos por el ordenamiento jurídico. De acuerdo con el positivismo de Hart, el juez en este caso contará con una "discrecionalidad judicial" para optar por una u otra posición ${ }^{19}$, lo cual se evidencia, en la práctica, con la decisiones mencionadas con ponencia del mismo magistrado. Esta discordancia iresponde a esos conceptos extralegales confundibles con la moral del juez? Un planteamiento dworkiniano -al igual que el hartiano- habría optado por dejar de lado los argumentos de conveniencia social, centrándose en los argumentos "de principio" ${ }^{10}$; es decir, en fundamentos normativos que regulan el caso concreto. No obstante, no se habría conformado con dos decisiones posibles, sino que habría buscado entre estas aquella que se identificase más con los principios emanados de la historia político-constitucional colombiana, llegando, así, a una única posible solución correcta.

Según este postulado, se partiría de la importancia de la coherencia en el ordenamiento jurídico ${ }^{21}$ a partir de la cual el derecho prevé una serie de mecanismos de protección a los derechos de los administrados. Estas herramientas, con un criterio de especialidad, se encargan de proteger las distintas afectaciones a las que se expone el ciudadano, partiendo del diseño fijado por el legislador. Así, en materia de protección de derechos constitucionales, se ha previsto la acción popular como un mecanismo especialmente ideado para la protección de las garantías colectivas de los administrados ${ }^{22}$. Por parte de la acción de tutela, desde la Constitución misma ${ }^{23}$ se posiciona como una herramienta en cabeza de toda persona para la protección de "sus derechos

CÉSAR Rodríguez, op. cit., p. 82.

Ibíd., p. 78.

"El enfoque del derecho como integridad no seria escéptico respecto a estas aparentes contradicciones y trataría de indagar cuáles son las razones que convierten un criterio como el del mérito en adecuado para solucionar determinados problemas y en cambio para otros se utiliza el criterio de las necesidades. El derecho como integridad trata de reconstruir la historia. Allí donde encuentra criterios contradictorios busca una explicación y exige que las distinciones entre criterios no se produzcan al azar sino que respondan a razones públicas y justificadas". Albert Casalmiglia, "El concepto de integridad en Dworkin", Doxa Cuadernos de Filosofía del Derecho, n. ${ }^{\circ} 12,1992$, pp. 170-171.

22 Tanto legalmente (Ley 472) como jurisprudencialmente: "En síntesis, de acuerdo con la jurisprudencia constitucional, se concluye que la acción popular es un derecho político, constitucional y fundamental, basado en los principios de autogobierno democrático, libertad individual y solidaridad, que tiene como propósito principal asegurar el goce efectivo de los derechos e intereses colectivos". Corte Constitucional, sentencia C-630 de 2011.

23 Artículo 86, Constitución Política. 
constitucionales fundamentales", la cual solo procederá "cuando el afectado no disponga de otro medio de defensa judicial, salvo que aquella se utilice como mecanismo transitorio para evitar un perjuicio irremediable". Por consiguiente, se delimita el ámbito subsidiario de protección de la acción de tutela, esto es, los derechos fundamentales individuales ante ausencia de otro mecanismo ${ }^{24}$. De ahí que la protección de derechos colectivos por medio de tutela sea excepcional y únicamente justificada en la afectación real a derechos individuales. Por lo tanto, cuando la afectación se dirige más a la comunidad generalmente considerada que al individuo, es decir, no se está ante una violación inmediata de la garantía individual (perjuicio irremediable), sino ante una dirigida al derecho de la "comunidad general que impida dividirlo o materializarlo en una situación particular ${ }^{\prime \prime 2}$, se deberá optar por una protección mediante la acción popular ${ }^{26}$. De lo contrario, se desfiguraría la esencia de la tutela y se llegaría al extremo de ordenar medidas de protección de derechos colectivos, antes de tutelar la violación de garantías individuales ${ }^{27}$-tal y como sucede en la sentencia que aquí se examina-, sin perjuicio de los problemas generados ante la posible solución de un mismo caso por dos jueces distintos.

Si se toma como referente el ius naturalismo racionalista, se partirá de una razón superior e imponible a todos los humanos, la cual debe ser el punto de arranque de toda aplicación del derecho. No se desconocerá la aplicación del derecho positivo, pero se optará por el derecho natural en caso de contradicción entre estos. Si bien el postulado kantiano de una razón evidenciable por

24 Sobre esto, encontramos pertinente la conclusión realizada en un salvamento de voto de la sentencia T-543 de 2017, el cual, respecto de los derechos colectivos de los consumidores consideró: "Por ende, éste cuenta con un mecanismo idóneo para su protección: la acción popular. Así, la acción de tutela no estaría llamada a prosperar por no cumplirse con el requisito de subsidiariedad. Y en gracia de discusión, si el asunto implicara un derecho fundamental, surge como cuestión insuperable la legitimación en la causa por activa, en tanto que los ciudadanos accionantes estarían actuando oficiosamente en nombre de todos los demás consumidores. Esta circunstancia ratifica que estamos ante un derecho colectivo". Corte Constitucional, sentencia T-543 de 2017, salvamento de voto, M.P. Carlos Bernal Pulido.

25 Sentencia T-659 de 2007

26 Se reitera que para que proceda la acción de tutela, se requiere "que la afectación del derecho colectivo también amena(ce) el derecho individualizado de la persona que interpone la acción de tutela, cuya protección no resulta efectiva mediante la presentación de una acción popular, sino que, por el contrario, debe ser evidente la urgencia en la intervención inmediata del juez de tutela". Corte Constitucional, sentencia T-517 de 2011, reiterando también en la sentencia C-253 de 2016.

27 Reconociendo esto, la Corte Constitucional denegó la acción de tutela interpuesta por habitantes de la región amazónica ante la afectación a sus derechos fundamentales por la utilización de glifosato en la región, considerando que "el artículo 88 constitucional prevé el mecanismo de las Acciones Populares, el que, además, permite al juzgador adoptar medidas cautelares, para evitar la realización de daños ambientales inminentes e irreparables". Sentencia SU-383 de 2003. 
todos fue un punto necesario para el desarrollo de nuestro sistema jurídico actual $^{28}$, el reconocimiento actual del relativismo moral impide una razón objetiva claramente diferenciable por cada individuo ${ }^{29}$. Esto conlleva a que el argumento de la razón natural pueda esconder las posiciones filosóficas del interprete, por lo que la decisión dependerá, por ejemplo, de lo libertario o autoritario que pueda ser el juez.

Por lo tanto, desde los ojos de un iusnaturalista, se podrían encontrar diferentes soluciones, basadas todas en una racionalidad abstractamente definida. Se podrá argumentar a favor de idoneidad de la tutela en el presente caso, acudiendo también a que los derechos individuales afectados deben primar ante tan flagrante violación, que el juez no puede posicionarse como un sujeto pasivo e instrumental del derecho positivo, sino que debe tomar las medidas necesarias para la correcta protección de los tutelantes, entre otros. Por lo que se estaría implícitamente dejando la solución del caso difícil a una expresión de la moralidad del juez y su percepción de los hechos (elemento que reconoce expresamente el realismo psicológico, como una "causa no jurídica de la decisión ${ }^{\prime \prime 30}$ ).

Tratándose de la postura realista, el juez analizaría en primer lugar las consecuencias que podría tener el optar por una u otra decisión (admitir o no la tutela), de esta manera, la decisión tendría su primer fundamento en el examen del derecho en función a sus fines y efectos ${ }^{31}$. Aquí se revela una convergencia entre las soluciones planteadas de los dworkinianos, los formalistas y los realistas, pues en el caso de estos últimos se optará también por declarar improcedente la tutela. Esto justificado en que, si bien se daría una especial atención a los argumentos de afectación al medio ambiente, los índices de deforestación, la afectación cuantificable a las fuentes hídricas y al aumento

28 Véase como ejemplo de esto el que, en el preámbulo de la declaración de derechos del hombre y el ciudadano, se dispuso que la asamblea ha "resuelto exponer, en una declaración solemne, los derechos naturales, inalienables y sagrados del hombre".

29 La base del derecho natural se estructura en principios indeterminados según los cuales debe hacerse el "bien", lo cual se evidencia en que "en estricto rigor, estos principios le imponen direccionalidad a nuestras acciones. Es decir, puesto que todo actuar se encuentra dirigido a un fin o fines que son, al nivel de esos principios, los objetos de las inclinaciones naturales, dichos preceptos marcan la dirección a la que debe apuntar el actuar humano: 'se debe hacer el bien y evitar el mal', 'no se debe hacer a los demás lo que no queremos que ellos hagan a nosotros', 'se debe obrar conforme a la recta razón'". SEbASTIÁN CONTRERAS, "La ley natural y su falta de determinación. Apuntes sobre la teoría clásica de la determinación del derecho natural", Boletín Mexicano de Derecho Comparado, año XLVII, n. ${ }^{\circ} 141,2014$, p. 851 .

30 Santiago Reyes Molina, "Jerome Frank: Realismo jurídico estadounidense y los hechos en el derecho", Eunomía. Revista en Cultura de la Legalidad, n. ${ }^{\circ}$ 10, 2016, p. 268.

31 José Ignacio Solar Cayón, "Karl N. Llewellyn: Algo de realismo sobre el realismo. Los orígenes del realismo jurídico americano", Eunomía. Revista en Cultura de la Legalidad, n. ${ }^{\circ} 2$, 2012, p. 186. 
climático, no se dejaría de lado el papel tanto de la acción de tutela como de la acción popular en el ordenamiento jurídico. Se trata de buscar decisiones acordes con el sistema desde una perspectiva externa (impacto en la sociedad), pero también desde una perspectiva interna (normas jurídicas) ${ }^{32}$.

Luego de examinada la solución dada por la Corte Suprema de Justicia al primer problema jurídico planteado en el caso objeto de análisis, se realiza el mismo ejercicio a propósito de la argumentación dada para saber si resulta atribuible a las autoridades accionadas el daño consistente en la deforestación de la Amazonía.

\section{DE LA VIOLACIÓN ATRIBUIBLE A LAS ENTIDADES ACCIONADAS}

A pesar de que metodológicamente se optó por dividir los argumentos de la Corte Suprema en dos acápites para abordar de forma separada los problemas jurídicos presentados, lo cierto es que la argumentación realizada no atiende a tal división. En efecto, el juez trató de manera conjunta los temas de la procedencia de la tutela con la violación del derecho y su atribución a las autoridades accionadas. Es posible notar que se entremezclaron los asuntos para, una vez señalada la importancia de la protección al medio ambiente en el ordenamiento colombiano (normativa interna e internacional), concluir que, en virtud del principio de solidaridad, resulta imperante proteger "el derecho al bienestar ambiental, tanto a los tutelantes, como a las demás personas que habitan y comparten el territorio amazónico, no solo el nacional, sino el extranjero, junto con todos los pobladores del globo terráqueo, incluido, los ecosistemas y seres vivos". Es importante notar la consideración expresa del juez de tutela al daño consumado y, particularmente, a cómo la amenaza de violación ${ }^{33}$ excede la esfera individual de los tutelantes, posicionándose por ende en una garantía en cabeza de la comunidad en general.

Partiendo de la certeza del daño ${ }^{34}$, la Corte Suprema comienza por realizar un contraste entre este y los principios de precaución, equidad intergeneracional y solidaridad. Respecto del primero, se consideró que la situación expuesta en este caso cumplía con la descripción de ser un peligro de daño irreversible

32 Carlos Diego Martínez Cinca, “CCómo decidir los 'casos difíciles'? Del giro pragmático de la jurisprudencia al consecuencialismo", Revista de Derecho, n. ${ }^{\circ} 43,2014$, p. 719.

33 Se hace especial énfasis en la amenaza de daño, pues es esta el principal argumento para tutelar los derechos fundamentales en cuestión. Es el alarmante escenario futuro el que justifica la protección judicial de un derecho colectivo al ambiente sano, lo cual se ve reflejado se reitera, en la ausencia de medidas concretas para la protección de los derechos al agua, la salud y la dignidad fundamento de la acción.

34 Sustentado en diferentes pruebas sobre la creciente tasa de deforestación y su correspondiente impacto en el medio ambiente. 
con un alto grado de probabilidad de ocurrencia, pero sin certeza científica de la misma, todo esto sustentando en los informes del IDEAM sobre la emisión de gases de efecto invernadero (GEI) y el detrimento a las fuentes hídricas. Estos hechos son también el sustento de protección a partir del principio de equidad intergeneracional. Con relación al principio de solidaridad, se consideró a esta como un punto crucial al momento de definir "el deber y corresponsabilidad del Estado colombiano en detener las causas que provocan la emisión de GEI provocada por la abrupta reducción boscosa de la Amazonía". Lo cual se ve complementado con la enunciación realizada de la protección constitucional del medio ambiente y, en especial, con la obligación de protección ambiental contraída por el Estado colombiano en la Convención marco sobre el cambio climático de París ${ }^{35}$.

Para continuar con la atribución de la violación, se debe recordar que el juez al momento de decidir debe partir tanto del artículo 86 de la Constitución, como en el artículo 1 del Decreto 2591 de $1991^{[36]}$, los cuales prevén por igual que la acción de tutela se incoará para la protección de derechos constitucionales fundamentales "vulnerados o amenazados por la acción o la omisión de cualquier autoridad pública". De ello se extrae literalmente que la violación necesita ser un resultado de una conducta atribuible a la autoridad pública. En este orden de ideas, debe existir una imputación fáctica y jurídica entre la conducta realizada y el daño generado. En el presente caso, estaríamos ante una presunta omisión por parte de las entidades demandadas que tienen la obligación general de dar protección a la selva de la Amazónica y que, de acuerdo con la Corte, se evidencia en el daño actual y el proyectado a futuro. Para el juez de tutela es claro que la ineficacia del actuar administrativo por lo que, en desarrollo del plurimencionado principio de solidaridad, encuentra que la Administración debe responder ante la situación con medidas correctivas y paliativas de distinta índole ${ }^{37}$.

36 Por el cual se reglamenta la acción de tutela consagrada en el artículo 86 de la Constitución Política.

37 Sin resultar en un listado exhaustivo, "i) la expansión desmedida de los cultivos ilícitos y de minería ilegal que destruyen irracionalmente el bosque amazónico; ii) llenar el vacío dejado por las FARC y paramilitares para hacer presencia activa del Estado en pro de la conservación de territorios amazónicos que en el contexto del conflicto armado fueron reconquistados por grupos insurgentes, depredadores sin piedad, colonizadores irracionales y en general personas y organizaciones al margen de la ley; iii) impedir y mitigar los crecientes incendios, la deforestación y la expansión irracional de la frontera agrícola; iv) la falta de prevención de las consecuencias inherentes a la apertura de vías, al otorgamiento

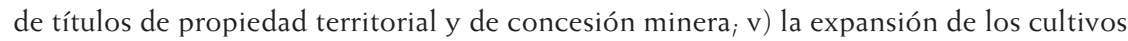
agroindustriales y de ganadería a gran escala; vi) la preservación de ese ecosistema por su importancia para regular el clima mundial ${ }_{;}$vii) la ausencia de cálculos científicos de la ascendente liberación de toneladas de carbono por las quemas y la pérdida de biomasa, 
La ineficacia del actuar administrativo deriva, en términos generales, del hecho de que exista un daño y una imputación normativa del mismo. Así, se consideró que los departamentos vinculados ${ }^{38}$ incumplieron con sus funciones, por tener la obligación de asistir a las corporaciones autónomas regionales (CAR) en la mitigación de la deforestación. En el caso de los municipios, se indicó que en razón de los altos niveles de deforestación, estos estaban incumpliendo lo dispuesto por el artículo 3 de la Ley 1551 de 2012, norma que consagra el deber de "velar por el adecuado manejo de los recursos naturales y del ambiente, de conformidad con la Constitución y la ley". En lo relacionado con las CAR y los parques nacionales involucrados, se optó por considerar que la violación les era imputable debido a que no habían realizado esfuerzos por detener la deforestación pues, conforme con los hechos, hay una omisión en la obligación evaluar, controlar, monitorear, investigar y sancionar las violaciones ambientales.

Si bien es posible indagar por la necesidad de un análisis probatorio más exhaustivo de la omisión de las entidades, o de la diligencia empleada por estas $^{39}$, la inconsistencia argumentativa central parece estar en la manera en cómo se vínculo a la Presidencia de la República, al Ministerio de Ambiente y Desarrollo Sostenible, y a la cartera de Agricultura y Desarrollo Rural pues, sin señalar las normas contravenidas o la relación de causalidad, se les ordenó

que constituye la cobertura vegetal ${ }_{i} \mathrm{y}$ viii) hacer frente al cambio climático por causa de la destrucción de la selva amazónica del territorio nacional".

"[...] como Amazonas, Caquetá, Guaviare y Putumayo".

39 Debe recordarse que la Corte Interamericana de Derechos Humanos ha considerado que la obligación de prevenir violaciones a derechos humanos es una obligación de medios y no de resultados, lo que de suyo implica una valoración de la diligencia emprendida por el Estado. Andrés González Serrano y Jesús Eduardo Sanabria Moyano, "Obligaciones de los Estados parte de la convención americana", Saber, Ciencia y Libertad, vol. 8, n. ${ }^{\circ} 2$, 2013, p. 43. A su vez, la Corte Interamericana, en opinión consultiva 23/17 solicitada por Colombia, concluyó respecto de la obligación de prevención de daños ambientales que esta: "debe cumplirse bajo un estándar de debida diligencia, el cual debe ser el apropiado y proporcional al grado de riesgo de daño ambiental. De esta forma, las medidas que un Estado deba adoptar para la conservación de ecosistemas frágiles serán mayores y distintas a las que corresponda adoptar frente al riesgo de daño ambiental de otros componentes del medio ambiente. Asimismo, las medidas para cumplir con este estándar pueden variar con el tiempo, por ejemplo, en base a descubrimientos científicos o nuevas tecnologías. No obstante, la existencia de esta obligación no depende del nivel de desarrollo, es decir, la obligación de prevención aplica por igual a Estados desarrollados como a aquellos en vías de desarrollo. Este Tribunal ha resaltado que la obligación general de prevenir violaciones a derechos humanos es una obligación de medio o comportamiento, no de resultado, por lo cual su incumplimiento no se demuestra por el mero hecho de que un derecho haya sido violado (supra párrs. 118 a 121). En el mismo sentido, la obligación de prevención prevista por el derecho ambiental es una obligación de medios, no de resultado". Opinión consultiva 23 del 15 de noviembre de 2017 OC 23/17, Corte Interamericana de Derechos Humanos, solicitada por la República de Colombia. 
la realización de diferentes planes o políticas públicas en coordinación con los sectores del sistema nacional ambienta ${ }^{40}$. Esto evidentemente corresponde más que a una atribución, a una medida responsiva de la magnitud de la afectación, la cual no es ajena a nuestro ordenamiento ${ }^{41}$, pero que en el caso concreto lleva a cuestionarse sobre la supuesta finalidad limitada a protección de derechos individuales.

Dejando de lado la consideraciones sobre el escenario procesal en el cual debe adelantarse el presente caso, la anterior argumentación puede examinarse bajo una postura positivista, atendiendo a la naturaleza del derecho colectivo protegido. Esto se fundamenta en los siguientes dos puntos:

- Desde un inicio el juez se encarga de sustentar el respaldo jurídico que le da nuestro ordenamiento a la protección del medio ambiente. No solo se resaltan abstractamente las obligaciones internacionales, sino que se define la necesidad de protección a partir de la obligación concreta contraída en el Convenio de París. Consiguientemente se acude al principio de solidaridad para justificar el deber de protección. Dicho principio está consagrado en el ordenamiento y, además, se posiciona como el punto de partida de los derechos colectivos y su protección ${ }^{42}$.

40 De esta manera, se puede considerar la ausencia de un juicio de responsabilidad pues "mientras que en el juicio de responsabilidad, como fundamento del deber de reparar, se atribuye la causación de un daño por una conducta activa u omisiva del agente a quien le pretendo exigir su reparación, en la determinación del deber de reparar fundamentado en la concreción normativa del principio de solidaridad se le atribuye necesariamente la reparación de un daño, no su causación. De allí que ninguna responsabilidad o declaratoria de responsabilidad pueda realizarse a ese efecto". Julí́n PIMIENTO, "Responsabilidad o solidaridad. el fundamento del deber de reparar en el ámbito de la responsabilidad extracontractual del Estado", Revista de Derecho Público, n. ${ }^{\circ} 36,2016$, p. 37. No obstante, si bien se tiene la previsión normativa que exige un juicio imputación, no se puede descartar la finalidad garantista de derechos constitucionales de la acción de tutela, la cual podría justificar el fundamento de restitución del derecho violado bajo el principio de solidaridad, con mayor respaldo que en materia de responsabilidad civil del Estado.

41 En ese sentido resulta ilustrativo el estado de cosas inconstitucionales declarado por la sentencia T-153 de 1998, referente a las condiciones indignas de hacinamiento de los reclusos de varios centros penitenciarios. Dicha situación al día de hoy requiere de pronunciamientos del juez constitucional, el cual para detener la violación de derechos fundamentales da órdenes al gobierno nacional como la de convocar al Consejo Superior de Política Criminal para la realización políticas públicas en la materia, tal y como sucedió en sentencia T-388 de 2013.

42 Así estos derechos "buscan la realización de una vida en relación con el conglomerado social, se muta el auto interés de protección ante los ataques de terceros y el Estado, por el principio de solidaridad". Juan Fernando Silva Henao, "Evolución y origen del concepto de 'Estado social' incorporado en la Constitución Política colombiana de 1991", Ratio Juris, vol. 7, n. ${ }^{\circ} 14,2014$, p. 146. De igual manera, la Corte Constitucional ha sido enfática en señalar que "los derechos colectivos se caracterizan porque son derechos de solidaridad, no son excluyentes, pertenecen a todos y cada uno de los individuos y no pueden existir sin la cooperación entre la sociedad civil, el Estado y la comunidad internacional". Sentencia C-377 de 2002 (bastardilla fuera del texto). 
Así, se da un primer sustento comprometido con el ideal político de la integridad $^{43}$

- La atribución jurídica se basó en obligaciones incumplidas por parte de las entidades accionadas. Para endilgar una violación por omisión resulta necesaria la utilización de disposiciones que obligaban a un actuar; de esta manera, la Corte se encargó señalar el marco normativo de las competencias de las entidades. Siguiendo esto, no debe olvidarse el fin para el cual se consagró la acción popular (también la tutela), este es la protección de derechos constitucionales. Por lo tanto, el juez puede optar por las medidas que considere necesarias para hacer cesar la violación ${ }^{44}$.

Sin embargo, no se puede dejar de lado que la atribución general a entidades como la Presidencia de la República rompe con la argumentación positivista, por lo que se ubica bajo un postulado realista que se enfoca en los efectos de la sentencia y en la función del derecho como un ideal de justicia material que, en este caso, deja de lado aspectos formales para exigir eficacia en la acción del Estado, vinculando a la máxima autoridad administrativa, la cual, además, se muestra como la más idónea para responder al presente caso.

Bajo una postura formalista, el fundamento principal giraría, al igual que desde la perspectiva positivista, alrededor del incumplimiento del marco competencial de las entidades, llegando así a una solución semejante a la de los positivistas.

La argumentación de la Corte evidencia inicialmente un postulado positivista, sin embargo, antes de proferir fallo se da otro giro tangencial atendiendo más a una posición realista del derecho. El juez de tutela, una vez puesta de presente la violación atribuible a las entidades accionadas y justificándose en una visión ecocéntrica de la naturaleza, procede a reconocer a la selva de la Amazonía como un "sujeto de derechos". Esta decisión es una clara respuesta al dilema moral y político consecuencia de la insuficiencia práctica de la normativa actual en materia de protección del medio ambiente. El deterioro causado a la selva del Amazonas ${ }^{45}$, a pesar de la protección consagrada en la Constitución e instrumentos internacionales, generó la necesidad de establecer

44 En materia de acciones populares "corresponde al juez popular tomar todas las medidas necesarias para superar los hechos y demás situaciones potencial o efectivamente generadores de la afectación de los intereses colectivos y restituir las cosas a su estado anterior". Consejo de Estado, Sección Tercera, sentencia del 2 de diciembre de 2013, exp. 76001-2331-000-2005-02130-01(AP). A su vez, en materia de tutela al juez "le está permitido entrar a examinar detenidamente los hechos de la demanda para que, si lo considera pertinente, entre a determinar cuáles son los derechos fundamentales vulnerados y/o amenazados, disponiendo lo necesario para su efectiva protección". Corte Constitucional, sentencia SU-484 de 2008.

45 Y al río Atrato como precedente fundante de la concesión de personalidad jurídica a un conjunto de elementos de la naturaleza. 
una conexión entre los derechos culturales y la protección al medio ambiente (derechos bioculturales) a través del posicionamiento como individuo a un conjunto de seres y objetos que, si bien podrían tener protección individual ${ }^{46}$, encuentran el sentido de su protección como partes de un todo ${ }^{47}$.

El desarrollo del anterior ejercicio académico muestra las inconsistencias que puede acarrear la interpretación y aplicación del derecho. Desde las diferentes teorías filosóficas se llegará muchas veces a una misma solución, pese a que el proceso para conseguirla pueda variar en cada oportunidad. Es claro que el derecho no tendrá siempre una solución para el caso concreto, lo que no obsta para que el operador del derecho quede a completa discreción en estos casos. Atendiendo al ideal del derecho como un sistema, se debe intentar la realización de la cuasi divina labor de consultar toda la historia político constitucional de un pueblo.

Como se puede observar en la decisión que se estudia, ya sea por la imposibilidad de solucionar cada caso, o por la ambigüedad del lenguaje -lo cual, consideramos, haría que hasta un semidios como Hércules termine argumentando bajo su propia convicción-, las decisiones judiciales no muestran la uniformidad que se esperaría. A partir del apartamiento del presente juez de tutela frente a fallos anteriores, se puede notar el componente humano que pretende ser omitido frente a la ficción de pensar en las corporaciones judiciales como un solo sujeto.

Ahora bien, parece moderada la decisión de reconocer el derecho, pero dejando que su desarrollo lo haga la administración especializada, es decir, son los jueces los que dan una solución inicial al caso difícil, no obstante, trasladan el deber desarrollar el resultado de las disertaciones jurídicas a diferentes organismos y entidades de naturaleza administrativa. Como se notará, no se trata de la habitual labor de reglamentación pues también se debe dar una solución final al vacío jurídico, y esto constituye también un "caso difícil". Es un cambio en la concepción del papel de la Administración en la interpretación del derecho, que habitualmente la postula como una mera ejecutora para entenderla como la competente en la solución de dilemas de esta estirpe, pero siempre aparecerá el juez como el que marca el punto de partida, o en su defecto ratifica las soluciones de la Administración.

46 Véase la protección a las especies animales y recursos naturales del Decreto 2811 de 1974 por ejemplo.

47 A pesar de que el juez intenta justificar esta decisión bajo principios internos del ordenamiento jurídico colombiano, difícilmente se llegaría a esa única decisión correcta del postulado dworkiniano, incluso, también resultaría difícil justificar dicha decisión bajo el margen de discrecionalidad judicial de los postulados positivistas de Hart. 


\section{UNA SOLUCIÓN QUE GENERA MÁS INTERROGANTES}

Consecuencia de la decisión de la Corte Suprema, el actuar de los particulares y principalmente del Estado debe ser cuidadoso en no violar los derechos de esta nueva tipología de persona, pues ya no se trata de una relación sujetoobjeto, sino que se realiza un cambio de paradigma en donde, ante una relación entre iguales, se necesita delimitar la posibilidad de injerencia en la esfera "personal" del sujeto.

Así, esta categoría se funda con el fin primario de dar una protección integral al medio ambiente, concretamente definido, en este caso, en la selva de la Amazonía. No obstante, a pesar de lo bien intencionada que puedan ser la Cortes, este planteamiento genera una considerable cantidad de preguntas sobre las implicaciones "secundarias" resultado de la disertación.

Se ha de entender que, desde el Código Civil, las personas se clasifican en naturales o jurídicas. Es evidente que no puede posicionarse al presente caso como una persona natural, por lo que ha de optarse por ubicarla como una ficción jurídica. Ahora bien, ¿cuáles son los derechos de los que es titular?, ¿no se desdibujaría la división entre derechos colectivos e individuales?, ¿quién ejerce su representación y bajo qué criterios se determina a este representante?, ¿el reconocimiento como sujeto de derechos está condicionado a una situación de amenaza?, cel conjunto de seres que componen esta "persona", lo hacen debido a criterios de ubicación territorial?, ¿se debe dar un tratamiento igual a todos los sujetos que se reconozcan de esta manera?

Tal y como reconoció la Corte Suprema, corresponde al Estado en general garantizar los derechos de este nuevo sujeto, pero es la Administración en concreto es la primera llamada a asegurarlos. Es el juez el que reconoció el punto de partida, pero corresponde al ejecutivo implementar los planes de reacción contra la deforestación y darle sentido a los derechos reconocidos. Por lo tanto, se deberá tener en cuenta que no se está regulando un objeto de protección en favor de la comunidad, sino que le corresponde fijar el estatuto de protección del desarrollo de la personalidad de la "selva del Amazonas", es decir, reglamentar la nueva norma introducida por la jurisprudencia.

El juez de tutela ordenó a la Presidencia, con participación activa de los tutelantes y las comunidades afectadas, fijar un plan de acción a corto, mediano y largo plazo respecto de la deforestación, así como la realización de un "pacto intergeneracional por la vida del amazonas colombiano (PIVAC)". Estas órdenes reconocen a la Administración pública como la competente para fijar los parámetros de protección de la "vida" de la selva del Amazonas, para lo cual se requerirá de perspectivas comparadas $\mathrm{y}$, principalmente, del conocimiento técnico en estos temas que caracteriza a la Administración de las demás ramas del poder público. Será este desarrollo el que le otorgue un 
valor más que semántico al reconocimiento del juez $z^{48}$. El ejecutivo deberá, por tanto, atendiendo a su legitimidad democrática -ausente en los órganos judiciales-y a su conocimiento técnico especializado, dar una solución adecuada al presente "caso difícil". Es este solo el punto de partida para la investigación y delimitación de esta nueva figura en el derecho administrativo colombiano.

\section{BIBLIOGRAFÍA}

Casalmiglia, Albert. "El concepto de integridad en Dworkin", Doxa Cuadernos de Filosofía del Derecho, n. ${ }^{\circ} 12,1992$.

Contreras, Sebastián. "La ley natural y su falta de determinación. Apuntes sobre la teoría clásica de la determinación del derecho natural", Boletín Mexicano de Derecho Comparado, año XLVII, n. ${ }^{\circ} 141,2014$.

De Prada Gracia, Aurelio. "Derechos humanos y derechos de la naturaleza. El individuo y la Pachamama", Cuadernos Electrónicos de Filosofía del Derecho, n. ${ }^{\circ}$ 27, 2013.

González Serrano, Andrés y Jesús Eduardo Sanabria Moyano. "Obligaciones de los Estados parte de la convención americana", Saber, Ciencia y Libertad, vol. 8, n. ${ }^{\circ}$ $2,2013$.

Martínez Cinca, Carlos Diego. "¿Cómo decidir los 'casos difíciles'? Del giro pragmático de la jurisprudencia al consecuencialismo", Revista de Derecho, n. ${ }^{\circ} 43,2014$.

48 Parte de la doctrina considera inoficiosa la postulación de unos derechos en cabeza de la naturaleza por considerar que esta figura no atiende al verdadero problema resultado de nuestro sistema económico que ve el medio ambiente como una "mercancía" y que, por tanto, lo que haces es desdibujar el concepto mismo de derecho, pues "si los derechos son siempre cualidades personales y sólo existen en la medida que son ejercidos por una persona, pues únicamente los individuos personales son sujetos de derechos, hablar de 'derechos de la naturaleza' supone no sólo atribuir a la naturaleza una condición personal de sujeto (y por consiguiente 'desnaturalizarla') sino también sustraer a la persona humana los derechos que se atribuyen a la naturaleza, 'despersonalizando' así al ser humano y también 'desnaturalizándolo' en la medida que se le despoja de su dimensión o relación 'natural"'. José SÁnchez PARGA, "Discursos retrovolucionarios: Sumak Kausay, derechos de la naturaleza y otros pachamamismos", Debate, n. ${ }^{\circ} 84,2011$, p. 39. Sin embargo, se considera que la progresiva eliminación de la frontera entre el humano y su entorno es lo que permite cambiar aquellas consecuencias de nuestro sistema económico sobre la naturaleza, el derecho en su labor de cambio social responde a la necesidad de entender al ser humano como parte de un todo, "de modo tal que el individuo, sin dejar de serlo, sin dejar de ser valioso en sí mismo, digno, con derechos humanos... acabe reconociéndose parte de la naturaleza, parte de la Pachamama". Aurelio de Prada Gracía, "Derechos humanos y derechos de la naturaleza. El individuo y la Pachamama", Cuadernos Electrónicos de Filosofía del Derecho, n. ${ }^{\circ} 27,2013$, p. 93. 
Pimiento, Julián, "Responsabilidad o solidaridad. el fundamento del deber de reparar en el ámbito de la responsabilidad extracontractual del Estado", Revista de Derecho Público, n. ${ }^{\circ}$ 36, 2016.

Reyes Molina, Santiago. "Jerome Frank: Realismo jurídico estadounidense y los hechos en el derecho", Eunomía. Revista en Cultura de la Legalidad, n. ${ }^{\circ}$ 10, 2016.

RodríGUEZ, CÉSAR, La decisión judicial. El debate Hart-Dworkin, Bogotá: Siglo del Hombre - Universidad de los Andes, 1997.

SÁnchez Parga, José, "Discursos retrovolucionarios: Sumak Kausay, derechos de la naturaleza y otros pachamamismos", Debate, n. ${ }^{\circ} 84,2011$.

Shapiro, Scott. Legalidad, Madrid: Marcial Pons, 2014.

Silva Henao, Juan Fernando. "Evolución y origen del concepto de 'Estado social' incorporado en la Constitución Política colombiana de 1991", Ratio Juris, vol. 7, n. ${ }^{\circ} 14,2014$.

Solar Cayón, José Ignacio. "Karl N. Llewellyn: Algo de realismo sobre el realismo. Los orígenes del realismo jurídico americano", Eunomía. Revista en Cultura de la Legalidad, n. ${ }^{\circ}$ 2, 2012. 